\title{
Comprehensive Selection of the Wood Properties of Paulownia Clones Grown in the Hilly Region of Southern China
}

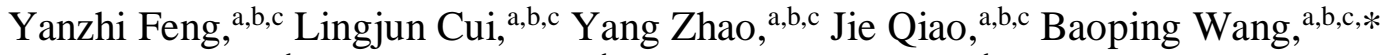
Chaowei Yang, ${ }^{a, b, c}$ Haijiang Zhou, ${ }^{\text {a,b,c }}$ and Delong Chang ${ }^{a, b, c}$

The wood properties of Paulownia clones determine their ultimate price and uses. This study selected superior clones with good color and mechanical properties using selection indexes. Variation in 23 5-year-old Paulownia clones was analyzed using genetic parameters, correlation analysis, and a comprehensive assessment of two color characteristics [color difference $(\Delta E)$ and whiteness $(W H)$ ] and six mechanical properties [density $(\rho)$, hardness of the tangential, radial, and end surfaces $\left(H_{t}, H_{r}\right.$, and $\left.H_{e}\right)$, and cleavage strength of the tangential and radial surfaces $\left(q_{t}\right.$, $\left.q_{r}\right)$ ]. There were significant differences $(p<0.01)$ in each of the eight traits among the 23 clones. There were significant negative phenotypic and genetic correlations between $\Delta E$ and $W H$. The six mechanical properties were significantly positively correlated genetically, showing significant positive phenotypic correlations with each other, except for $\rho, H_{t}$, and $q_{t}$. With a selection rate of $8.70 \%$, clones MB04 and L01 were selected as superior using the comprehensive selection index. Compared with the control (9501), the genetic gains of clones MB04 and L01 in $\triangle E, W H, \rho$, $q_{r}, q_{t}, H_{e}, H_{r}$, and $H_{t}$ were $0.40,0.21,10.32,12.57,14.81,26.05,28.04$, and $6.84 \%$, respectively, and the actual gains were $0.59,0.31,17.21$, $28.45,28.09,34.90,40.08$, and $11.12 \%$.

Keywords: Paulownia clones; Color characterization; Mechanical properties; Phenotypic variation; Genetic variation; Comprehensive selection

Contact information: a: Paulownia R\&D Center of State Administration of Forestry and Grassland, Zhengzhou 450003, P. R. China; $b$ : Non-Timber Forest R\&D Center, Chinese Academy of Forestry, Zhengzhou 450003, P. R. China; c: Key Laboratory of Non-timber Forest Germplasm Enhancement \& Utilization of State Forestry Administraion, Zhengzhou 450003, P. R. China;

* Corresponding author: paulowniawang@163.com;

\section{INTRODUCTION}

Approximately $82 \%$ of the continental biomass and over $50 \%$ of the terrestrial biodiversity worldwide are in forest ecosystems (Petit and Hampe 2006; Neale et al. 2011; Duan et al. 2016). The abundant trait variation of trees enhances their adaptability to various environments and offers the possibility of selecting trees with ideal characteristics (Hoffmann et al. 2011; Lopes et al. 2015; Matuszewski et al. 2015). Most tree characteristics are quantitative traits regulated by multiple genes (Bradshaw et al. 2000; Wang et al. 2010). In the past, the selection criteria for good trees were primarily growth characteristics, adaptability, and the ability to resist pests and diseases. Although breeding programs need to consider the basic timber properties, these have not received much attention (Huda et al. 2014). However, timber quality (color and mechanical properties) 
directly influences its economic value. To achieve greater economic benefits, the wood color and mechanical properties must be assessed comprehensively.

Paulownia species are very adaptable, extremely fast-growing tree species that are widely cultivated in subtropical and warm temperate regions (Ayrilmis and Kaymakci 2013; Candan et al. 2013; Salari et al. 2013). They are mainly used for timber and for producing ameliorating microclimates in intercropping systems (Wu et al. 2014). Paulownia plantations are also used to reduce soil denudation and for tree-crop intercropping patterns and farmland shelter because of their advanced root systems and adaptability to various soil conditions (Smiley 1961; Lucas-Borja et al. 2011). Paulownia wood is good for fabricating plywood, paper, and furniture because of its velvety texture and excellent grain patterns (Beel et al. 2005; Ashori et al. 2009). Therefore, Paulownia has an important role in easing the imbalance between wood supply and demand. They are fast-growing, broad-leaved species that should be promoted for timber plantations (Wu et al. 2014). For many years, Paulownia clones were selected using direct selection for a single trait (e.g., growth rate, stem form, wood color, etc.) or a single trait permutation selection method (gradually achieving genetic improvement of multiple traits). Few studies have examined the comprehensive improvement of multiple traits (Cotterill and Jackson 1985; Cotterill 1985; Qiu et al. 2014; Zhao et al. 2017), which greatly reduces the selection effect in multiple trait breeding.

In this study, a comprehensive evaluation of the color characteristics and mechanical properties of 23 Paulownia clones was performed. The variance and genetic parameters of eight traits were analyzed, and superior clones with good color and mechanical properties were identified using a comprehensive selection index. The purpose of this research was to select comprehensively of middle-mature forest in terms of wood color and mechanical properties, and to guide the genetic improvement, processing, and utilization of Paulownia.

\section{EXPERIMENTAL}

\section{General Introduction to the Research Region}

The study site was located in Chongyang County, Xianning city, Hubei Province, China $\left(29^{\circ} 33^{\prime} \mathrm{N}, 114^{\circ} 01^{\prime} \mathrm{E}\right)$, a hilly region at $180 \mathrm{~m}$ above sea level with 15 to $25^{\circ}$ slopes. The mean annual temperature, precipitation, and daylight hours were $15.8^{\circ} \mathrm{C}, 1988.5 \mathrm{~mm}$, and $1775 \mathrm{~h}$, respectively. The soil is a yellow-red soil with a frost-free period of 263 days.

One-year-old root piles of Paulownia clones with a ground diameter of $3.5 \pm 0.5$ $\mathrm{cm}$ were used for afforestation in the spring of 2008. The density of planting was $4 \times 5 \mathrm{~m}$, and each tree was given $3 \mathrm{~kg}$ of organic fertilizer as base fertilizer. The 23 Paulownia clones used in the experiment were selected out by super seedling selection and seedling stage check, and they were planted according to a completely randomized block design with three blocks, and each block contained randomly plots of the 23 clones. Within each plot, there were six trees of the same clone planted. The control group was clone 9501, a natural hybrid of Paulownia fortunei which has been widely planted in China. The experimental forest around the protection tree lines was tended regularly. All of the Paulownia clones used in this study were cut down in the spring of 2013, at which time, their average height and diameter at breast height were $8.17 \pm 0.75 \mathrm{~m}$ and $18.96 \pm 1.36 \mathrm{~cm}$, respectively. 


\section{Production of Test Pieces}

For each clone, three representative trees were sampled for each block. One 8-cmlong disk was cut at 1.36 to $1.44 \mathrm{~m}$ above the base of the tree, and three 6-cm-long disks were cut at 1.18 to $1.36 \mathrm{~m}$ above the base of the tree. Each disk was marked in four directions, the east, south, west, and north. The sample logs were sawn, and test specimens were made according to Fig. 1. The hardnesses of the end, radial, and tangential surfaces were measured in 36 specimens with end $\times$ radial $\times$ tangential dimensions of $70 \mathrm{~mm} \times 50$ $\mathrm{mm} \times 50 \mathrm{~mm}$. The density and two color traits were measured in the same 36 specimens shaved with end $\times$ radial $\times$ tangential dimensions of $50 \mathrm{~mm} \times 50 \mathrm{~mm} \times 50 \mathrm{~mm}$. The cleavage strength of the tangential and radial surfaces were determined for 36 specimens each, which measured $50 \mathrm{~mm} \times 20 \mathrm{~mm} \times 20 \mathrm{~mm}$ (end $\times$ radial $\times$ tangential).

Table 1. 23 Paulownia Clones Used in this Study

\begin{tabular}{|c|c|c|c|c|}
\hline No. & Clone Identity & Clone Source & Female Parent & Male Parent \\
\hline 1 & M01 & selection of plus tree & Paulownia tomentosa & -- \\
\hline 2 & M02 & natural hybrid & Paulownia tomentosa & ** \\
\hline 3 & B01 & natural hybrid & Paulownia fortunei & ** \\
\hline 4 & B02 & natural hybrid & Paulownia fortunei & ** \\
\hline 5 & B03 & natural hybrid & Paulownia fortunei & ** \\
\hline 6 & B05 & natural hybrid & Paulownia fortunei & ** \\
\hline 7 & B07 & natural hybrid & Paulownia fortunei & ** \\
\hline 8 & B09 & natural hybrid & Paulownia fortunei & ** \\
\hline 9 & L01 & selection of plus tree & Paulownia elongata & -- \\
\hline 10 & $\mathrm{C} 01$ & selection of plus tree & Paulownia fargesii & -- \\
\hline 11 & MB01 & artificial hybrid & Paulownia tomentosa & Paulownia fortunei \\
\hline 12 & MB02 & artificial hybrid & Paulownia tomentosa & Paulownia fortunei \\
\hline 13 & MB04 & artificial hybrid & Paulownia tomentosa & Paulownia fortunei \\
\hline 14 & MB05 & artificial hybrid & Paulownia tomentosa & Paulownia fortunei \\
\hline 15 & MB06 & artificial hybrid & Paulownia tomentosa & Paulownia fortunei \\
\hline 16 & MB07 & artificial hybrid & Paulownia tomentosa & Paulownia fortunei \\
\hline 17 & MB08 & artificial hybrid & Paulownia tomentosa & Paulownia fortunei \\
\hline 18 & MB10 & artificial hybrid & Paulownia tomentosa & Paulownia fortunei \\
\hline 19 & MB11 & artificial hybrid & Paulownia tomentosa & Paulownia fortunei \\
\hline 20 & BM01 & artificial hybrid & Paulownia fortunei & Paulownia tomentosa \\
\hline 21 & BM02 & artificial hybrid & Paulownia fortunei & Paulownia tomentosa \\
\hline 22 & BL01 & artificial hybrid & Paulownia fortunei & Paulownia elongata \\
\hline 23 & $9501(\mathrm{CK})$ & natural hybrid & Paulownia fortunei & ** \\
\hline
\end{tabular}

\section{Research Methods}

The total color difference and whiteness indices were measured on the radial surfaces of dry specimens using a Konica Minolta CR-400 with a D65 standard source. The specimen density index was measured the GB/T 1933-2009 (2009) standard. The specimens were kept in an oven at $60{ }^{\circ} \mathrm{C}$ for $4 \mathrm{~h}$ and then maintained at $103 \pm 2{ }^{\circ} \mathrm{C}$ until a constant weight was reached; this was deemed the dry weight. The mass $(\mathrm{m})$ was measured with an AL204 electronic balance from Mettler Toledo (precision $0.0001 \mathrm{~g}$ ). The length $(l)$, width $(w)$, and height $(h)$ were measured with digital vernier calipers (precision 0.01 $\mathrm{mm})$, and the full dry densities were calculated using the formula $\rho=m /(l \times w \times h)$. 


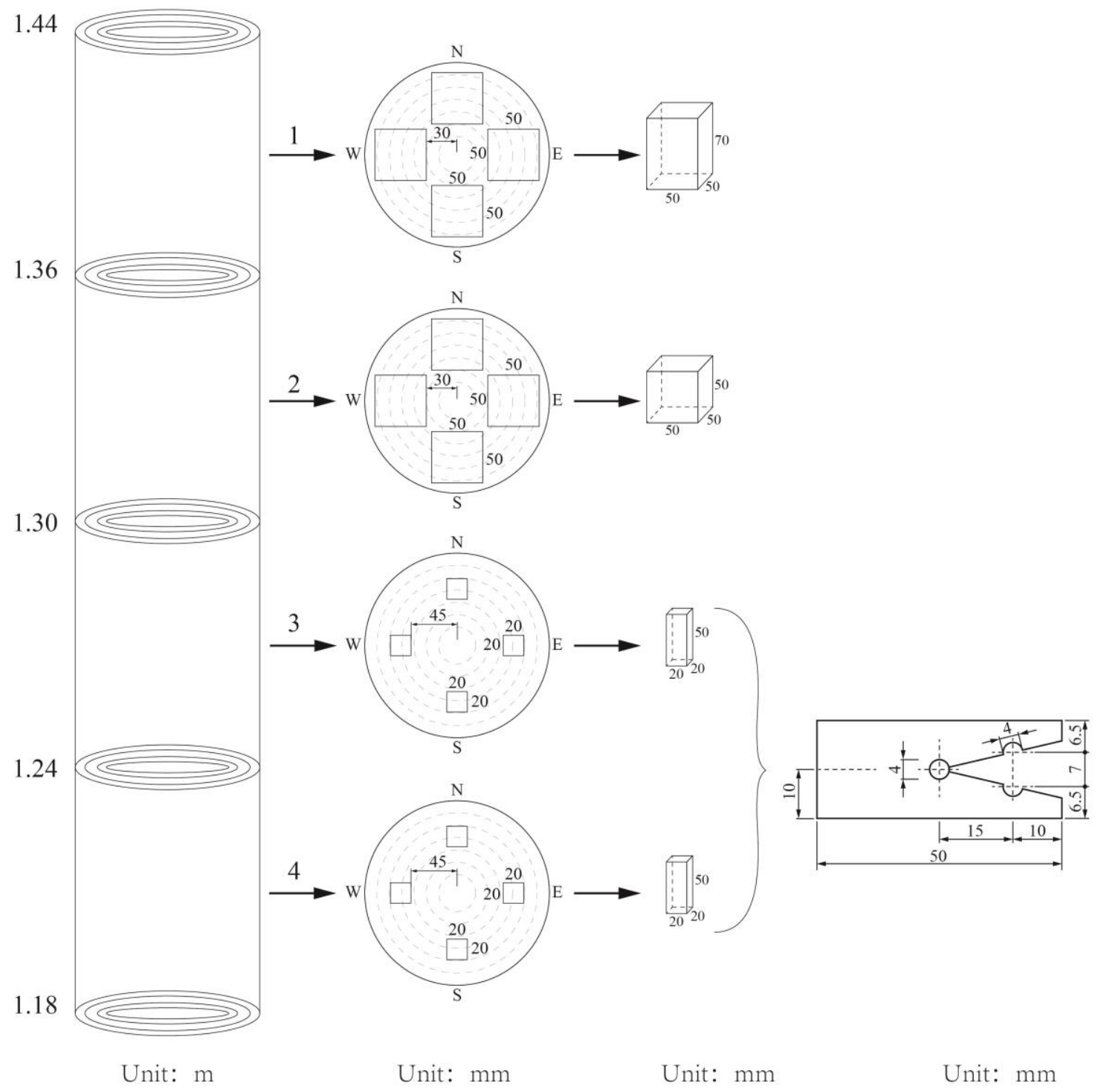

Fig. 1. Sampling methods for discs and logs and test samples for the color characteristics and mechanical properties of wood. Test samples for the (1) hardness, (2) density and color, (3) cleavage strength of tangential surfaces, and (4) cleavage strength of radial surfaces

The cleavage strength could only be measured for one surface per specimen because this requires making a wedge incision. The cleavage strengths of radial and tangential specimens were measured according to the GB/T 1942-2009 (2009) standard. First, the moisture contents of the specimens were adjusted to $12 \%$. After measuring the width $(b)$ of surfaces used for the wedge incisions, the specimens were loaded on the mechanical test machine and destroyed within 0.2 to 0.5 min by increasing the load at a uniform rate; the breaking load was labeled as $P_{\max }$. The cleavage strength $(q)$ at $12 \%$ moisture content was calculated using the formula $q=P_{\max } / b$.

The hardness index was measured according to GB/T 1941-2009 (2009). The moisture content was the same as in the cleavage strength test. After the specimen was loaded on the mechanical test machine, the steel head was pressed into the test face to a 
depth of $5.64 \mathrm{~mm}$ at a uniform speed of 3 to $6 \mathrm{~mm} / \mathrm{min}$; the load at this point was denoted $H_{\mathrm{w}}$. The radial, tangential, and end faces of each specimen were tested twice, and the average was used as hardness of each surface. The hardness $(H)$ at $12 \%$ moisture content was calculated using the formula $H=H_{\mathrm{w}}$.

\section{Statistical Analysis}

Given a Paulownia clones available for testing with $b$ blocks, each consisting of $n$ plots planted, and using the value of a single observation as the statistical unit, the linear analysis of variance (ANOVA) model for this analysis was $x_{i j k}=\mu+\alpha_{i}+\beta_{j}+\alpha \beta_{i j k}+e_{i j k}$, where $\mu$ is the population mean, $\alpha_{i}$ is the clone effect, $\beta_{j}$ is the block effect, $\alpha \beta_{i j k}$ is the interaction effect between clone and block, and $e_{i j k}$ is the random error (Pâques et al. 2013). The formula for clonal repeatability is $H^{2}=\frac{\sigma_{a}^{2}}{\sigma_{a}^{2}+\sigma_{a b}{ }^{2} / \mathrm{b}+\sigma_{e}^{2} / n b}$, where $\sigma_{a}^{2}$ is the clonal variance component, $\sigma_{a b}{ }^{2}$ is the variance component of the interaction effect between clone and block, and $\sigma_{e}^{2}$ is the variance component of the random error (Xu 2006). The phenotypic variation coefficient is $P C V=\frac{S}{\bar{x}} \times 100 \%$ and the genetic variation coefficient is $G C V=\frac{\sqrt{\sigma_{a}^{2}}}{\bar{x}} \times 100 \%$, where $S$ and $\bar{x}$ are the phenotypic standard deviation and the mean of a trait, respectively (Lai et al. 2014). The phenotype correlation coefficient is $r_{p 12}=\frac{\operatorname{Cov}_{p 12}}{\sqrt{\sigma_{p 1}{ }^{2} \sigma_{p 2}^{2}}}$ and the genetic correlation coefficient is $r_{g 12}=\frac{\operatorname{Cov} v_{g 12}}{\sqrt{\sigma_{g 1}^{2} \sigma_{g 2}^{2}}}$, where $\sigma_{p 1}^{2}$ and $\sigma_{p 2}{ }^{2}$ are the phenotypic variances of the two traits, $\sigma_{g 1}{ }^{2}$ and $\sigma_{g 2}{ }^{2}$ are the genetic variances of the two traits, and $\operatorname{Cov}_{p 12}$ and $\operatorname{Cov}_{g 12}$ are the phenotypic and genetic covariances of the two traits $(\mathrm{Xu} 2006)$. The genetic gain is $\Delta G=\left(H^{2} M / \bar{x}\right) \times 100 \%$, and the actual gain is $G=$ $(M / \bar{x}) \times 100 \%$, where $M$ is the difference between the means of a trait in the selected clonal population and the control (Zhao 2002).

The selection for multiple traits in the 23 Paulownia clones was assessed using the Smith-Hazel selection index (Cotterill and Dean 1990), which estimates the economic weight of each trait by using an equal weight method $(W)$. Thus, $W$ is calculated as $W_{i}=$ $1 / \sigma_{i}$, where $\sigma_{i}$ is the phenotypic standard deviation of each trait (Cotterill and Jackson 1985). Depending on the breeding objectives, to adjust for the appropriate multiple (Zhao et al. 2015), the selection index is calculated as $I=b_{1} x_{1}+b_{2} x_{2}+\ldots b_{n} x_{n}$, where $b=P^{-}$ ${ }^{1} G W$, and $b_{i}, x_{i}$, and $\sigma_{i}$ are the index coefficient, mean, and phenotypic standard deviation of each trait, respectively, $P$ and $G$ are the phenotypic and genetic variance covariance matrix, respectively, and $W$ is the economic weight vector of each trait (Wang et al. 2012).

\section{RESULTS AND DISCUSSION}

\section{Difference Analysis and Genetic Parameter Estimation}

Variation among clones is the basis of clonal breeding. The size of the variation coefficient not only reflects the degree of variation within a group but also decides the 
selection space (Zhao et al. 2012; Du et al. 2015). The coefficient of genetic variation reflects the degree of variation in traits caused by genetic factors; a large value indicates that the trait has a relatively large potential for improvement among different clones (Wang et al. 2012). Table 2 shows the ANOVA and genetic parameter estimation for the eight traits studied. The F values of the eight traits ranged from 3.3037 to 22.0960. The results show that these traits were weakly affected by the external environment, and there were real genetic differences. Therefore, large gains can be obtained by selecting clones (Huang et al. 2005). The genetic and phenotypic variation coefficients ( $G C V$ and $P C V$ ) of cleavage strength were both in the order $q_{t}>q_{r}$; the $P C V$ of hardness was in the order $H_{t}>$ $H_{r}>H_{e}$; and the $G C V$ of hardness was in the order $H_{r}>H_{t}>H_{e}$. The $G C V$ and $P C V$ of cleavage strength and hardness were the largest, followed by $\rho$ and $\Delta E$, and then by $W H$. The change in $G C V$ ranged from 5.5474 to $50.2532 \%$, and the change in $P C V$ ranged from 3.5141 to $21.9049 \%$. The results indicated that was easiest to select clones with a high $q$ and $H$, and then $\rho, \Delta E$, and $W H$.

Table 2. Analysis of Variance and Genetic Parameter Estimation

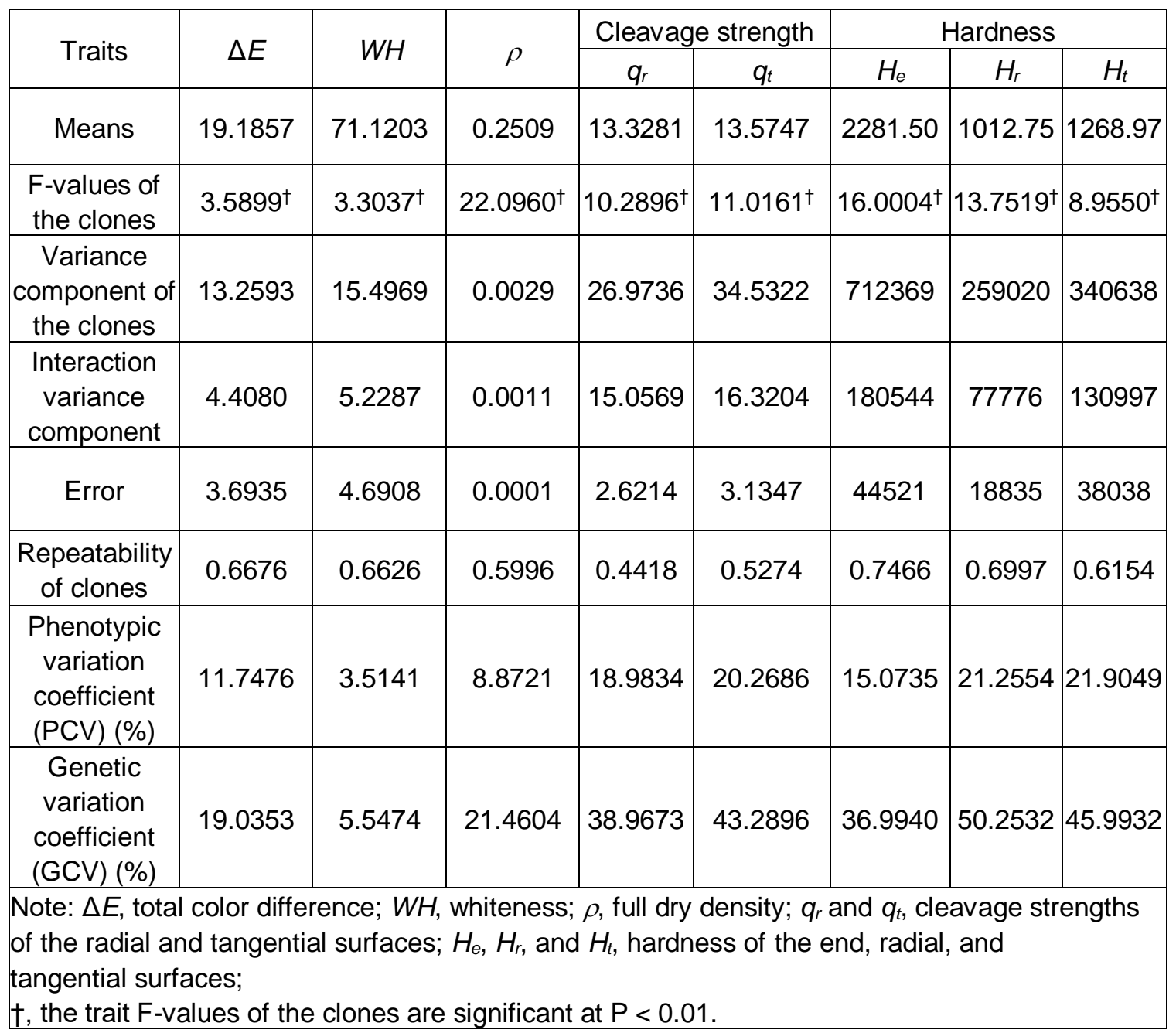

Table 3 shows Duncan's multiple comparisons of the eight traits among the 23 Paulownia clones. 
Table 3. Duncan's Multiple Comparison of the Color and Mechanical Properties of the 23 Paulownia Clones

\begin{tabular}{|c|c|c|c|c|c|c|c|c|}
\hline Traits & \multirow{2}{*}{$\Delta E$} & \multirow{2}{*}{$W H$} & \multirow{2}{*}{$\rho$} & \multicolumn{2}{|c|}{ Cleavage strength } & \multicolumn{3}{|c|}{ Hardness } \\
\hline & & & & $q_{r}$ & $q_{t}$ & $H_{e}$ & $H_{r}$ & $H_{t}$ \\
\hline M01 & $19.10 \pm 2.03 \mathrm{bcd}$ & $71.35 \pm 2.22 \mathrm{abc}$ & $0.2206 \pm 0.0077$ I & $11.83 \pm 1.37$ ghij & $11.54 \pm 1.88 \mathrm{~cd}$ & $1961.23 \pm 146.71 \mathrm{ij}$ & $785.58 \pm 85.32 \mathrm{i}$ & $974.18 \pm 159.43 \mathrm{j}$ \\
\hline M02 & $21.41 \pm 1.79 \mathrm{a}$ & $68.56 \pm 2.17 \mathrm{e}$ & $0.2346 \pm 0.0143 \mathrm{jk}$ & $12.21 \pm 2.34 \mathrm{fghi}$ & $12.79 \pm 2.80 \mathrm{bc}$ & $1880.09 \pm 225.51 \mathrm{j}$ & $853.98 \pm 114.75 \mathrm{hi}$ & $1065.91 \pm 84.01 \mathrm{ij}$ \\
\hline B01 & $19.22 \pm 1.21 \mathrm{bcd}$ & $71.13 \pm 1.24 \mathrm{abc}$ & $0.2621 \pm 0.0104 \mathrm{~cd}$ & $14.79 \pm 1.94 \mathrm{abc}$ & $14.79 \pm 1.94 \mathrm{a}$ & $2294.83 \pm 176.86 \operatorname{defg}$ & $1062.74 \pm 173.24$ bcde & $1279.69 \pm 86.30$ defg \\
\hline B02 & $18.76 \pm 2.01 \mathrm{bcd}$ & $71.46 \pm 2.42 \mathrm{abc}$ & $0.2544 \pm 0.0315$ defg & $15.04 \pm 2.04 \mathrm{ab}$ & $15.21 \pm 1.98 \mathrm{a}$ & $2381.77 \pm 224.89$ cdef & $1142.59 \pm 105.49 b c$ & $1437.10 \pm 176.75 \mathrm{bcd}$ \\
\hline B03 & $18.22 \pm 1.94 \mathrm{~cd}$ & $72.21 \pm 2.30 \mathrm{ab}$ & $0.2463 \pm 0.0115 \mathrm{ghi}$ & $11.50 \pm 1.75$ hij & $10.79 \pm 0.92 \mathrm{de}$ & $2118.83 \pm 193.20 \mathrm{ghi}$ & $925.45 \pm 925.45 \mathrm{fgh}$ & $1099.79 \pm 176.11 \mathrm{ghij}$ \\
\hline B05 & $21.33 \pm 2.08 \mathrm{a}$ & $68.91 \pm 2.17 \mathrm{de}$ & $0.2765 \pm 0.0089 a b$ & $13.38 \pm 3.00$ cdef & $14.08 \pm 3.01 \mathrm{ab}$ & $2584.75 \pm 229.59 b$ & $1319.37 \pm 206.78 \mathrm{a}$ & $1624.29 \pm 210.63 a$ \\
\hline B07 & $19.04 \pm 1.66 \mathrm{bcd}$ & $71.11 \pm 1.78 \mathrm{abc}$ & $0.2417 \pm 0.0319$ hij & $11.13 \pm 3.61 \mathrm{ij}$ & $10.67 \pm 2.72 \mathrm{de}$ & $2192.44 \pm 420.99 \mathrm{fgh}$ & $877.73 \pm 198.35 \mathrm{ghi}$ & $1112.22 \pm 209.62$ fghij \\
\hline B09 & $18.91 \pm 2.64 \mathrm{bcd}$ & $71.41 \pm 2.94 \mathrm{abc}$ & $0.2553 \pm 0.0238$ defg & $12.46 \pm 3.83$ fghi & $13.88 \pm 4.47$ bcde & $2286.03 \pm 260.90$ defg & $885.55 \pm 190.45 \mathrm{ghi}$ & $1219.47 \pm 164.10$ efghi \\
\hline L01 & $18.97 \pm 1.03 \mathrm{bcd}$ & $71.40 \pm 1.08 \mathrm{abc}$ & $0.2674 \pm 0.0150 \mathrm{bc}$ & $14.29 \pm 1.42 \mathrm{bcd}$ & $15.00 \pm 1.80 \mathrm{a}$ & $2561.43 \pm 229.01 \mathrm{bc}$ & $1077.72 \pm 165.22$ bcde & $1236.42 \pm 173.18$ efghi \\
\hline $\mathrm{C} 01$ & $19.07 \pm 0.95 \mathrm{bcd}$ & $71.22 \pm 1.02 \mathrm{abc}$ & $0.2278 \pm 0.0147 \mathrm{kl}$ & $13.38 \pm 2.00 \mathrm{cdef}$ & $13.83 \pm 1.79 \mathrm{ab}$ & $1988.98 \pm 229.27 \mathrm{ij}$ & $846.37 \pm 171.75 \mathrm{hi}$ & $1080.33 \pm 233.66$ hij \\
\hline MB01 & $18.62 \pm 1.62 \mathrm{~cd}$ & $71.59 \pm 1.85 \mathrm{abc}$ & $0.2562 \pm 0.0135$ defg & $16.00 \pm 2.24 \mathrm{a}$ & $15.33 \pm 1.93 \mathrm{a}$ & $2544.31 \pm 173.61 \mathrm{bc}$ & $1060.68 \pm 70.82 \mathrm{bcde}$ & $1311.74 \pm 81.11 \mathrm{cde}$ \\
\hline MB02 & $18.34 \pm 3.28 \mathrm{~cd}$ & $72.30 \pm 3.53 a b$ & $0.2514 \pm 0.0126$ efgh & $13.67 \pm 1.81$ bcdef & $14.08 \pm 2.30 \mathrm{ab}$ & $2374.38 \pm 192.82 \mathrm{cdef}$ & $1088.03 \pm 101.16 \mathrm{bcd}$ & $1219.49 \pm 107.51$ efghi \\
\hline MB04 & $17.99 \pm 1.36 \mathrm{~d}$ & $72.27 \pm 1.97 \mathrm{ab}$ & $0.2845 \pm 0.0186 a$ & $14.46 \pm 2.52 \mathrm{bcd}$ & $14.79 \pm 2.01 \mathrm{a}$ & $2877.96 \pm 269.50 \mathrm{a}$ & $1307.21 \pm 188.66 \mathrm{a}$ & $1579.42 \pm 191.70 a b$ \\
\hline MB05 & $18.44 \pm 1.61 \mathrm{~cd}$ & $71.91 \pm 1.87 \mathrm{ab}$ & $0.2612 \pm 0.0099$ cde & $10.58 \pm 1.58 j$ & $9.58 \pm 1.08 \mathrm{e}$ & $2409.54 \pm 178.54$ bcde & $1173.06 \pm 159.75 b$ & $1463.30 \pm 265.96 \mathrm{abc}$ \\
\hline MB06 & $20.20 \pm 2.29 a b c$ & $70.18 \pm 2.77$ bcde & $0.2466 \pm 0.0136 \mathrm{ghi}$ & $14.54 \pm 2.07 \mathrm{abcd}$ & $14.92 \pm 3.29 \mathrm{a}$ & $2114.96 \pm 313.86 \mathrm{ghi}$ & $888.38 \pm 172.28 \mathrm{ghi}$ & $1132.59 \pm 243.78$ efghij \\
\hline MB07 & $19.23 \pm 3.00 \mathrm{bcd}$ & $71.05 \pm 3.39 \mathrm{abcd}$ & $0.2604 \pm 0.0148$ cde & $13.38 \pm 1.38 \mathrm{cdef}$ & $13.67 \pm 1.44 \mathrm{ab}$ & $2318.31 \pm 262.95$ def & $1062.96 \pm 164.55$ bcde & $1420.56 \pm 386.60 \mathrm{bcd}$ \\
\hline MB08 & $17.55 \pm 2.23 d$ & $72.93 \pm 2.55 \mathrm{a}$ & $0.2505 \pm 0.0293$ efgh & $14.88 \pm 2.21 \mathrm{abc}$ & $14.92 \pm 2.90 \mathrm{a}$ & $2019.01 \pm 424.31 \mathrm{hij}$ & $955.28 \pm 285.18$ efgh & $1417.87 \pm 601.44 \mathrm{bcd}$ \\
\hline MB10 & $19.37 \pm 1.69 \mathrm{bcd}$ & $71.05 \pm 1.84 \mathrm{abcd}$ & $0.2644 \pm 0.0230 \mathrm{~cd}$ & $14.00 \pm 1.26$ bcde & $14.21 \pm 1.25 \mathrm{ab}$ & $2462.14 \pm 299.70 \mathrm{bcd}$ & $1114.09 \pm 274.67 \mathrm{bcd}$ & $1421.92 \pm 340.88 \mathrm{bcd}$ \\
\hline MB11 & $19.37 \pm 2.22 \mathrm{bcd}$ & $70.85 \pm 2.38 \mathrm{abcd}$ & $0.2428 \pm 0.0110$ hij & $12.75 \pm 1.14$ efgh & $12.67 \pm 1.19 \mathrm{bc}$ & $2242.36 \pm 256.18$ efg & $949.88 \pm 94.32$ efgh & $1151.41 \pm 174.20$ efghij \\
\hline BM01 & $19.45 \pm 1.64 \mathrm{bcd}$ & $70.89 \pm 1.69 \mathrm{abcd}$ & $0.2495 \pm 0.0120 \mathrm{fgh}$ & $13.63 \pm 2.64$ bcdef & $14.00 \pm 1.82 \mathrm{ab}$ & $2193.45 \pm 296.71 \mathrm{fgh}$ & $1003.33 \pm 101.14$ defg & $1210.22 \pm 111.78$ efghi \\
\hline BM02 & $17.90 \pm 2.37 d$ & $72.54 \pm 2.59 a b$ & $0.2584 \pm 0.0177$ cdef & $15.00 \pm 1.60 \mathrm{ab}$ & $14.92 \pm 1.44 \mathrm{a}$ & $2434.77 \pm 370.99$ bcde & $1057.98 \pm 133.76$ bcde & $1299.31 \pm 238.34$ cdef \\
\hline BL01 & $20.70 \pm 2.98 \mathrm{ab}$ & $69.49 \pm 3.21 \mathrm{cde}$ & $0.2385 \pm 0.0145 \mathrm{ij}$ & $13.15 \pm 1.87$ defg & $14.58 \pm 2.44 \mathrm{a}$ & $2295.47 \pm 268.81 \operatorname{defg}$ & $1040.77 \pm 217.42$ cdef & $1215.65 \pm 217.71$ efghi \\
\hline $9501(\mathrm{CK})$ & $18.59 \pm 1.29 \mathrm{~cd}$ & $71.61 \pm 1.37 \mathrm{abc}$ & $0.2328 \pm 0.0063 \mathrm{jk}$ & $10.58 \pm 2.31 \mathrm{j}$ & $11.08 \pm 2.77 \mathrm{de}$ & $1923.54 \pm 121.24 j$ & $786.57 \pm 124.45 \mathrm{i}$ & $1266.84 \pm 146.54$ defgh \\
\hline
\end{tabular}


The $\Delta E$ of clones MB08, BM02, MB04, B03, MB02, and MB05 were lower than that of the control. The $W H$ of clones MB08, BM02, MB02, MB04, B03, and MB05 were higher than that of the control. The $\rho$ values of the other clones were higher than the control, except for $\mathrm{C} 01$ and M01. More than half of the clones had significantly higher $q$ and $H$ values than the control, except for the value of $H_{t}$.

\section{Correlational Analysis}

Table 4 shows the correlation coefficients between the phenotypic and genetic mechanical properties for the 23 clones. The phenotypic and genetic correlation coefficients of $\Delta E$ and $W H$ were -0.9751 and -0.9987 , respectively, and both were significant. The six mechanical traits showed strong significant $(P<0.01)$ positive genetic intercorrelations. There were also significant $(P<0.01)$ positive phenotypic correlations between members of each pair, except for $q_{t}, H_{t}$, and $\rho$. The phenotypic correlation coefficients between color and the mechanical traits were not significantly different from each other, except for $q_{r}$, while the genetic correlation coefficients between color and the mechanical traits differed significantly, except for $H_{r}$ and $H_{t}$. The correlation coefficients between tree traits can provide a theoretical reference for a genetic improvement strategy for trees and is important in tree breeding (He et al. 2002). For the eight traits we studied, the correlation coefficients between members of each pair varied; phenotypic and genetic correlation coefficients differed not only in magnitude but also in sign (positive and negative). The genetic correlation coefficients for $H_{e}, H_{r}$, and $H_{t}$ between each pair were $0.9422,0.8684$, and 0.6947 . Therefore, the hardness of wood can be expressed by a single one of these to save time and costs. Similarly, cleavage strength can be expressed using $q_{r}$ or $q_{t}$.

Table 4. Correlation Coefficients Between the Color and Mechanical Properties of the Clones

\begin{tabular}{|c|c|c|c|c|c|c|c|c|}
\hline $\begin{array}{c}\text { Correlation } \\
\text { Coefficients }\end{array}$ & $\Delta E$ & $W H$ & $\rho$ & $q_{r}$ & $q_{t}$ & $H_{e}$ & $H_{r}$ & $H_{t}$ \\
\hline$\Delta E$ & & $-0.9751^{\dagger}$ & 0.0832 & $0.1498^{\dagger}$ & -0.0151 & 0.0782 & -0.0243 & 0.0936 \\
\hline$W H$ & $-0.9987^{\dagger}$ & & 0.0886 & $0.1511^{\dagger}$ & -0.0112 & 0.0803 & -0.0224 & 0.0926 \\
\hline$\rho$ & $-0.2549^{\dagger}$ & $0.2795^{\dagger}$ & & $0.1448^{\star}$ & 0.1027 & $0.5763^{\dagger}$ & $0.5889^{\dagger}$ & $0.4409^{\dagger}$ \\
\hline$q_{r}$ & $-0.2524^{\dagger}$ & $0.3147^{\dagger}$ & $0.5032^{\dagger}$ & & $0.4078^{\dagger}$ & $0.1543^{\dagger}$ & $0.1414^{*}$ & $0.1373^{*}$ \\
\hline$q_{t}$ & $0.1926^{\dagger}$ & $-0.1282^{*}$ & $0.3262^{\dagger}$ & $0.9947^{\dagger}$ & & $0.1302^{*}$ & $0.1619^{\dagger}$ & 0.1058 \\
\hline$H_{e}$ & $-0.1322^{\star}$ & $0.1457^{\star}$ & $0.9861^{\dagger}$ & $0.5902^{\dagger}$ & $0.4011^{\dagger}$ & & $0.6072^{\dagger}$ & $0.3323^{\dagger}$ \\
\hline$H_{r}$ & 0.0986 & -0.0698 & $0.9879^{\dagger}$ & $0.6149^{\dagger}$ & $0.4415^{\dagger}$ & $0.9422^{\dagger}$ & & $0.5110^{\dagger}$ \\
\hline$H_{t}$ & -0.0830 & 0.0833 & $0.9872^{\dagger}$ & $0.4543^{\dagger}$ & $0.2869^{\dagger}$ & $0.6947^{\dagger}$ & $0.8684^{\dagger}$ & \\
\hline
\end{tabular}

Notes:

Phenotypic (genetic) correlation coefficients are in the upper (lower) triangle;

${ }^{*}$ and ${ }^{\dagger}$ indicate significant correlations at the $5 \%$ and $1 \%$ levels, respectively.

\section{Multi-Trait Index Selection}

The economic weights of the eight traits shown in Table 5 were determined by the equal weight method. The economic weights of $\Delta E$ and $W H$ were -0.4437 and 0.4001 , respectively. $\rho$ had the highest economic weight (44.9172), followed by $q_{r}(0.3952)$ and $q_{t}$ (0.3635). $H_{e}, H_{r}$, and $H_{t}$ had the lowest economic weights, 0.0029, 0.0046, and 0.0036, respectively. Based on the correlations with the other traits, the unconstrained and equal 
weight methods were used to build multiple trait exponential equations using equal weights of the traits, emphasizing color traits, and emphasizing mechanical properties, respectively. Table 6 shows the combined selection progress of the equations and genetic progress on the traits. Using the eight traits as the evaluation indices, the 23 clones were comprehensively evaluated using the exponential equations $\mathrm{I}_{1}, \mathrm{I}_{2}$, and $\mathrm{I}_{3}$, respectively. The comprehensive selection values were 3.2477, 4.7385, and 9.1449, respectively, and the genetic progress of the eight traits was positive, except $\Delta E$.

Table 5. Economic Weights of the Eight Traits

\begin{tabular}{|c|c|c|c|c|c|c|c|c|}
\hline Selection indices & $\Delta E$ & $W H$ & $\rho$ & $q_{r}$ & $q_{t}$ & $H_{e}$ & $H_{r}$ & $H_{t}$ \\
\hline $\mathrm{I}_{1}$ & -0.4437 & 0.4001 & 44.9172 & 0.3952 & 0.3635 & 0.0029 & 0.0046 & 0.0036 \\
\hline $\mathrm{I}_{2}$ & -1.3311 & 1.2003 & 44.9172 & 0.3952 & 0.3635 & 0.0029 & 0.0046 & 0.0036 \\
\hline $\mathrm{I}_{3}$ & -0.4437 & 0.4001 & 134.7517 & 1.1857 & 1.0904 & 0.0087 & 0.0139 & 0.0108 \\
\hline
\end{tabular}

According to the $21.7 \%$ selection ratio, clones MB04, B05, MB02, L01, and B02 were selected as excellent clones using equation $\mathrm{I}_{1}$; clones MB04, MB02, BM02, L01, and MB05 were selected using equation $\mathrm{I}_{2}$; and clones MB04, B05, B02, L01, and MB10 were selected using equation $\mathrm{I}_{3}$. All of the equations selected clones MB04 and L01, indicating that clones MB04 and L01 were excellent clones, with good color and mechanical properties.

Table 7 shows the mean value of each trait for the two selected clones (MB04 and L01) under a selection ratio of $8.70 \%$. Compared with the control, the total color difference and whiteness of clone L01 were slightly worse, and all of the other traits were improved to some extent, which might be related to the fact that clone L01 was rooted in Paulownia elongata, while clones MB04 and 9501 were both rooted in Paulownia fortunei, and the wood color index of Paulownia fortunei is better than that of Paulownia elongata (Chang et al. 2013). The increase in the six mechanical traits was large and ranged from $11.14 \%$ to $51.60 \%$, followed by values for $\Delta E$ and $W H$, which were increased by $0.61 \%$ and $0.31 \%$, respectively. The genetic and actual gains of the selected population were calculated by comparing the mean values of the traits of the selected population with those of the control; the results are shown in Figure 2. The actual gains of $H_{r}, H_{e}$, and $q_{r}$ of the selected population were the highest, at 40.08, 34.90, and $28.45 \%$, respectively, followed by $q_{t}$ (28.09\%), $\rho(17.21 \%)$, and $H_{t}(11.12 \%)$, and the lowest actual gains were in $\Delta E(0.59 \%)$ and $W H(0.31 \%)$. The highest genetic gains for the selected population were in $H_{r}(28.04 \%)$ and $H_{e}(26.05 \%)$, followed by $q_{t}(14.81 \%), q_{r}(12.57 \%), \rho(10.32 \%), H_{t}(6.84 \%), \Delta E$ $(0.40 \%)$, and $W H(0.21 \%)$ (Fig. 2).

A successful breeding program should involve various traits (Sun et al. 2005), but trait selection (quantity and type) directly affects the precision of selective breeding. The more traits are selected and the characteristic information represented is comprehensive but may not be able to select out the ideal clones, the fewer traits are selected and it may be easy to choose, but its representative's information may be incomplete (Feng et al. 2017). Therefore, different combinations of selected traits should be developed according to specific breeding objectives. 
Table 6. Combined Selection and Genetic Progress on the Traits

\begin{tabular}{|c|c|c|c|c|c|c|c|c|c|c|}
\hline \multirow{2}{*}{ No. } & \multirow{2}{*}{$\begin{array}{l}\text { The Multiple Traits } \\
\text { Exponential Equations }\end{array}$} & $\begin{array}{c}\text { Combined } \\
\text { Selection }\end{array}$ & \multicolumn{8}{|c|}{ Genetic Progress } \\
\hline & & $\Delta H$ & $\Delta E$ & $W H$ & $\rho$ & $q_{r}$ & $q_{t}$ & $H_{e}$ & $H_{r}$ & $H_{t}$ \\
\hline $\mathrm{l}_{1}$ & $\begin{array}{l}1.9623 x_{1}+2.3926 x_{2}+ \\
20.9507 x_{3}-0.1998 x_{4}+ \\
0.5407 x_{5}+0.0012 x_{6}+ \\
0.0122 x_{7}-0.0006 x_{8}\end{array}$ & 3.2477 & -0.4720 & 0.5927 & 0.0112 & 1.0014 & 0.7929 & 208.93 & 119.99 & 125.28 \\
\hline $\mathrm{I}_{2}$ & $\begin{array}{l}2.8968 x_{1}+4.2996 x_{2}+ \\
45.2920 x_{3}-0.3666 x_{4}+ \\
0.4803 x_{5}+0.0004 x_{6}+ \\
0.0132 x_{7}-0.0028 x_{8}\end{array}$ & 4.7385 & -1.0481 & 1.2127 & 0.0085 & 0.7857 & 0.3803 & 148.86 & 70.33 & 82.87 \\
\hline $\mathrm{I}_{2}$ & $\begin{array}{l}4.9523 x_{1}+5.2708 x_{2}+ \\
38.5109 x_{3}-0.4327 x_{4}+ \\
1.6825 x_{5}+0.0045 x_{6}+ \\
0.0355 x_{7}+0.0005 x_{8}\end{array}$ & 9.1449 & -0.1274 & 0.2136 & 0.0115 & 1.0153 & 0.9293 & 219.67 & 134.02 & 135.02 \\
\hline
\end{tabular}


This study analyzed variation in two color characteristics $(\Delta E$ and $W H)$ and six mechanical properties $\left(\rho, H_{t}, H_{r}, H_{e}, q_{t}\right.$, and $\left.q_{r}\right)$ in 23 5-year-old Paulownia clones using genetic parameter evaluation, correlation analysis, and comprehensive assessment. Ultimately, clones MB04 and L01 were selected as superior using the comprehensive selection index under a selection rate of $8.70 \%$. The actual and genetic gains of the selected group were improved compared with the control.

Table 7. Means of the Eight Traits of the Three Paulownia Clones

\begin{tabular}{|c|c|c|c|c|c|c|c|c|}
\hline Clones & $\Delta E$ & $W H$ & $\rho$ & $q_{r}$ & $q_{t}$ & $H_{e}$ & $H_{r}$ & $H_{t}$ \\
\hline MB04 & 17.9867 & 72.2686 & 0.2845 & 14.4583 & 14.7917 & 2877.96 & 1307.21 & 1579.42 \\
\hline L01 & 18.9675 & 71.3976 & 0.2674 & 14.2917 & 15.0000 & 2561.43 & 1077.72 & 1236.43 \\
\hline $9501(\mathrm{CK})$ & 18.5912 & 71.6095 & 0.2328 & 10.5833 & 11.0833 & 1923.54 & 786.57 & 1266.84 \\
\hline
\end{tabular}

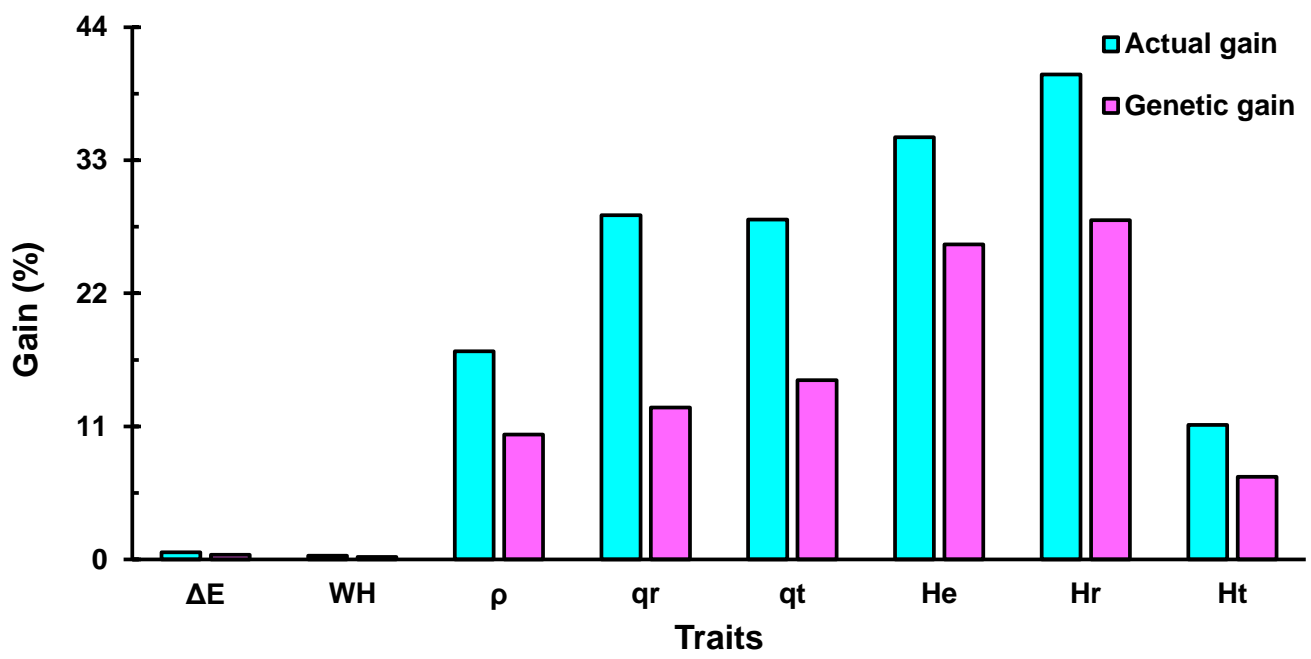

Fig. 2. Genetic and actual gains of the traits at a selection ratio of $8.70 \%$

\section{CONCLUSIONS}

1. With a selection rate of $8.70 \%$, clones MB04 and L01 were selected as superior clones using the comprehensive selection index among the 23 Paulownia clones. Compared with the control, the genetic gains of the two clones MB04 and L01 in $\Delta E$, $W H, \rho, q_{r}, q_{t}, H_{e}, H_{r}$, and $H_{t}$ were $0.40,0.21,10.32,12.57,14.81,26.05,28.04$, and $6.84 \%$, respectively, and the actual gains were $0.59,0.31,17.21,28.45,28.09,34.90$, 40.08 , and $11.12 \%$.

2. Abundant variation was found in the eight traits among the 23 Paulownia clones; the phenotypic variation coefficients all exceeded $11.75 \%$, except for $W H$ and $\rho$, while the genetic variation coefficients exceeded $19.04 \%$, except for $W H$.

3. The repeatabilities of all eight traits of the 23 Paulownia clones were high, and ranged from 0.4418 to 0.7466 .

4. The phenotypic and genetic correlations of $H_{e}, H_{r}$, and $H_{t}$ showed strong significant (p $<0.01$ ) positive, Therefore, the hardness of wood can be expressed by a single one of 
these to save time and costs. Similarly, cleavage strength can be expressed using $q_{r}$ or $q_{t}$.

\section{ACKNOWLEDGMENTS}

The authors are grateful for the support of the National Key R\&D Program of China (Grant No. 2017YFD0600506).

The English in this document has been checked by at least two professional editors, both native speakers of English. For a certificate, please see: http://www.textcheck.com/certificate/3gdKG8

\section{REFERENCES CITED}

Ashori, A., and Nourbakhsh, A. (2009). "Studies on Iranian cultivated Paulownia - A potential source of fibrous raw material for paper industry," European Journal of Wood and Wood Products 67(3), 323-327. DOI: 10.1007/s00107-009-0326-0

Ayrilmis, N., and Kaymakci, A. (2013). "Fast growing biomass as reinforcing filler in thermoplastic composites: Paulownia elongata wood," Industrial Crops and Products 43, 457-464. DOI: 10.1016/j.indcrop.2012.07.050

Beel, M., Davis, S., Murphy, J., and Piper, P. (2005). "Product potential of Paulownia timber," Australian Forestry 68(1), 3-8. DOI: 10.1080/00049158.2005.10676219

Bradshaw, H. D., Ceulemans, R., and Davis, J. (2000). "Emerging model systems in plant biology: Poplar (Populus) as a model forest tree," Journal of Plant Growth Regulation 19(3), 306-313. DOI: 10.1007/s003440000030

Candan, Z., Korkut, S., and Unsal, O. (2013). "Effect of thermal modification by hot pressing on performance properties of Paulownia wood boards," Industrial Crops and Products 45, 461-464. DOI: 10.1016/j.indcrop.2012.12.024

Chang, D.L., Huang, W.H., and Zhang, Y.L. (2013). "Wood color differences from four paulownia species," Journal of Northeast Forestry University 41(8), 102-112. (In Chinese)

Cotterill, P. P., and Dean, C. A. (1990). "Successful tree breeding with index selection," Commonwealth Scientific and Industrial Research Organisation, Division of Forestry and Forest Products, Canberra, Australia.

Cotterill, P. P. (1985). "On index selection. II. Simple indices which require no genetic parameters or special expertise to construct," Silvae Genetica (Germany, FR) 34, 2-3, 64-69.

Cotterill, P. P., and Jackson, N. (1985). "On index selection. I. Methods of determining economic weight," Silvae Genetica 34, 2-3, 56-63.

Du, C. Q., Xu, Y. Z., and Sun, X. M. (2015). "Variation of growth and early selection of Larix kaempferi clones in sub-alpine area of western Hubei Province," Journal of Huazhong Agricultural University 34(3), 19-23. (In Chinese)

Duan, H. J., Cao, S., and Zheng, H. Q. (2016). "Variation in the growth traits and wood properties of Chinese fir from six provinces of southern China," Forests 7(9), 192. DOI: 10.3390/f7090192

Feng, Y. Z., Qiao, J., and Wang, B. P. (2017). "Comprehensive selection of main 
phenotypic characters of paulownia clones in the hilly area of southern China," Forest Research 30(6), 969-976. (In Chinese)

GB/T 1933-2009. (2009). "Method for determination of the density of wood," Standardization Administration of China, Beijing, China.

GB/T 1941-2009. (2009). "Method of testing in hardness of wood," Standardization Administration of China, Beijing, China.

GB/T 1942-2009. (2009). "Method of testing in cleavage stregth of wood," Standardization Administration of China, Beijing, China.

He, G. P., Chen, Y. T., and Zhang, G. W. (2002). "Genetic analysis and family selection for main traits of growth and wood quality of Chinese fir," Forest Research 15(5), 559-563. (In Chinese)

Hoffmann, A. A., and Sgrò, C. M. (2011). "Climate change and evolutionary adaptation," Nature 470(7335), 479-485. DOI: 10.1038/nature09670

Huang, S. X., Shi, J. S., and Li, L. (2005). "Seletion of superior clones of Chinese fir for fibre wood," Journal of Nanjing Forestry University (Natural Sciences Edition) 29 (5), 21-24. (In Chinese)

Huda, A. A. S. M., Koubaa, A., and Cloutier, A. (2014). "Variation of the physical and mechanical properties of hybrid poplar clones," BioResources 9(1), 1456-1471. DOI: 10.15376/biores.9.1.1456-1471

Lai, M., Sun, X. M., and Chen, D. S. (2014). "Age-related trends in genetic parameters for Larix kaempferi and their implications for early selection," BMC Genetics 15(1), S10. DOI: 10.1186/1471-2156-15-S1-S10

Li, S. W., Jiang, Y. Z., and Wang, G. Y. (2004). "Genetic analysis and comprehensive evaluation for multi traits in section aigeiros clones," Journal of Beijing Forestry University 26(3), 36-40. (In Chinese)

Lopes, M. S., El-Basyoni, I., and Baenziger, P. S. (2015). "Exploiting genetic diversity from landraces in wheat breeding for adaptation to climate change," Journal of Experimental Botany 66(12), 3477-3486. DOI: 10.1093/jxb/erv122

Lucas-Borja, M. E., Wic-Baena, C., and Moreno, J. L. (2011). "Microbial activity in soils under fast-growing Paulownia (Paulownia elongata $x$ fortunei) plantations in Mediterranean areas," Applied Soil Ecology 51, 42-51. DOI: 10.1016/j.apsoil.2011.08.011

Matuszewski, S., Hermisson, J., and Kopp, M. (2015). "Catch me if you can: Adaptation from standing genetic variation to a moving phenotypic optimum," Genetics 200(4), 1255-1274. DOI: 10.1534/genetics.115.178574

Neale, D. B., and Kremer, A. (2011). "Forest tree genomics: growing resources and applications," Nature Reviews Genetics 12(2), 111-122. DOI: 10.1038/nrg2931

Pâques, L. E., del Carmen García-Casas, M., and Charpentier, J. P. (2013). "Distribution of heartwood extractives in hybrid larches and in their related European and Japanese larch parents: Relationship with wood colour parameters," European Journal of Forest Research 132(1), 61-69. DOI: 10.1007/s10342-012-0654-1

Petit, R. J., and Hampe, A. (2006). "Some evolutionary consequences of being a tree," Annual Review of Ecology, Evolution, and Systematics 37, 187-214. DOI: 10.1146/annurev.ecolsys.37.091305.110215

Qiu, Q. D., Mo, W. J., and Wang, N. (2014). "Selection of excellent wood color paulownia fortunei individuals," Forest Research 27(2), 277-283. (In Chinese)

Salari, A., Tabarsa, T., and Khazaeian, A. (2013). "Improving some of applied properties of oriented strand board (OSB) made from underutilized low quality paulownia 
(Paulownia fortunie) wood employing nano-SiO 2 ," Industrial Crops and Products 42, 1-9. DOI: 10.1016/j.indcrop.2012.05.010

Smiley C. J. (1961). "A record of Paulownia in the tertiary of North America," American Journal of Botany 48(2), 175-179. DOI: 10.1002/j.1537-2197.1961.tb11622.x

Sun, X. M., Zhang, S. G., and Li, S. Y. (2005). "Multi-traits selection of open-pollinated Larix kaempferi families for pulpwood purpose," Scientia Silvae Sinicae 41(4), 4854. (In Chinese)

Wang, K., Li, M. Y., and Hakonarson, H. (2010). "Analysing biological pathways in genome-wide association studies," Nature Reviews Genetics 11(12), 843-854. DOI: $10.1038 / \mathrm{nrg} 2884$

Wang, R. H., Hu, D. H., and Zheng, H. Q. (2012). "Clonal variation in growth and wood quality and the multi-trait index selection of Chinese fir," Scientia Silvae Sinicae 48(3), 45-50. (In Chinese)

Wu, L. C., Wang, B. P., and Qiao, J. (2014). "Effects of trunk-extension pruning at different intensities on the growth and trunk form of Paulownia fortunei," Forest Ecology and Management 327, 128-135. DOI: 10.1016/j.foreco.2014.05.008

$\mathrm{Xu}$, J. R. (2006). “Quantitative genetics in forestry,” Beijing: Higher Education Press, China.

Zhao, C. K. (2002). "A study on optimum age and gain for early selection of superior clone in Cunninghamia lanceolata hook," Scientia Silvae Sinicae 38(4), 53-60. (In Chinese)

Zhao, M. X., Yan, C. Q., and Wang, W. (2015). "Relationship between selection of Pinus massoniana families and Folium Pini," China Journal of Chinese Materia Medica 40(9), 1699-1704. (In Chinese)

Zhao, X. Y., Ma, K. F., and Shen, Y. B. (2012). "Characteristic variation and selection of forepart hybrid clones of Sect. Populus.," Journal of Beijing Forestry University 34(2), 45-51. (In Chinese)

Zhao, Y., Qiao, J., and Wang, B. P. (2017). "Comprehensive selection of growth and stem form of superior paulownia clones in the hilly region of southern China," Journal of Beijing Forestry University 39(9), 32-40. (In Chinese)

Article submitted: July 4, 2019; Peer review completed: September 3, 2019; Revised version received and accepted: December 18, 2019; Published: December 20, 2019. DOI: $10.15376 /$ biores.15.1.1098-1111 